\title{
caja de ahorros de Hamburgo
}

\author{
SCHRAMM y ELINGIUS, arquitectos
}

La ampliación del edificio-sede de la Caja de Ahorros de Hamburgo

venía haciéndose necesaria, y cuando se dispuso de solar adecuado se emprendió.

Este solar es contiguo al viejo edificio y queda separado de él por un pasaje, sobre el que se construyó,

desde la antigua a la nueva edificación, un puente, bajo el cual está situado

el gran hall de la Caja de Ahorros.

Este puente se realizó

con una estructura de hormigón pretensado,

a base de cuatro vigas que van de edificio

a edificio,

salvando un vano de $17 \mathrm{~m}$, "soldadas"

en sus extremos a ocho machos de hormigón por medio de armaduras pretensadas.

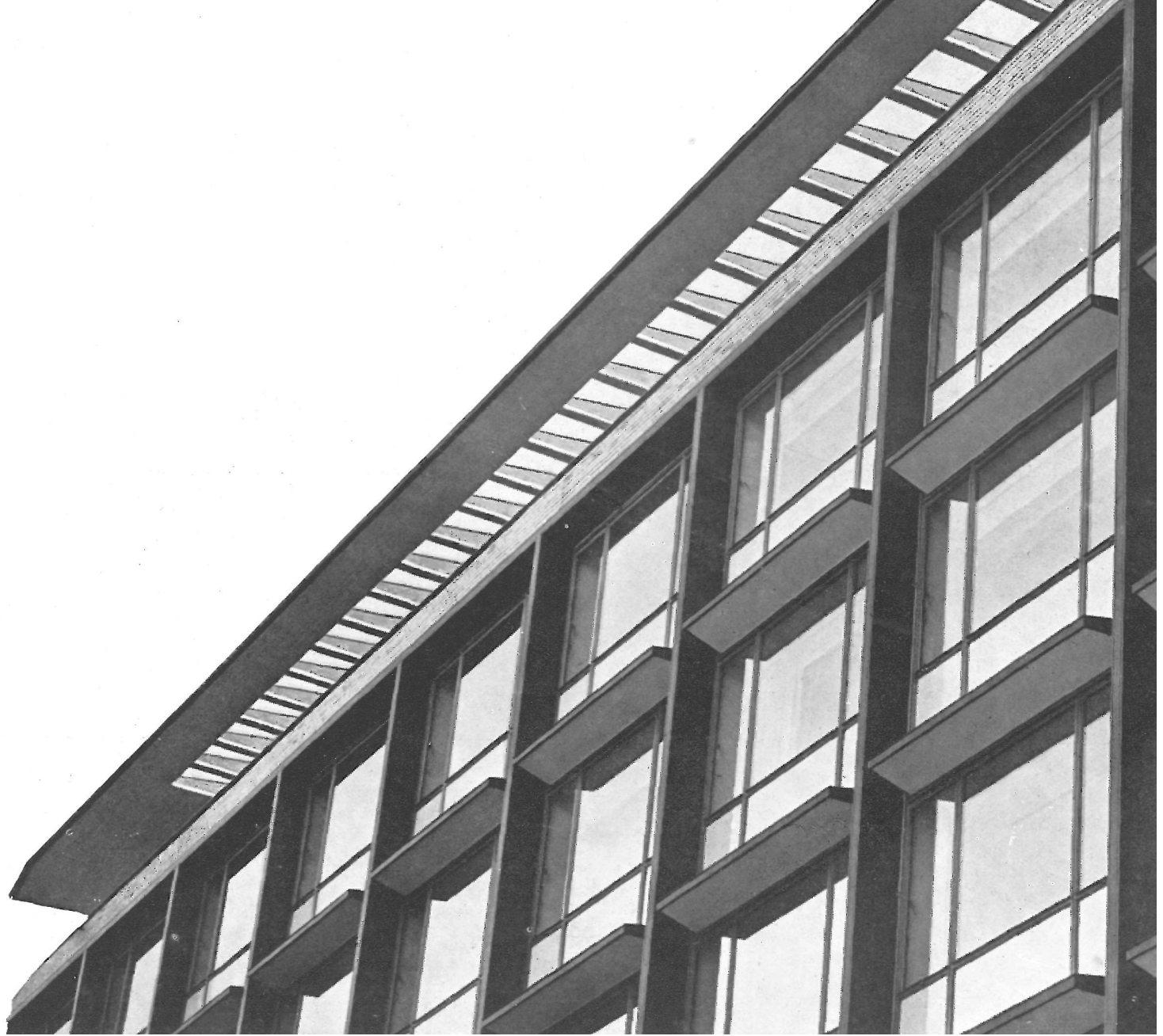




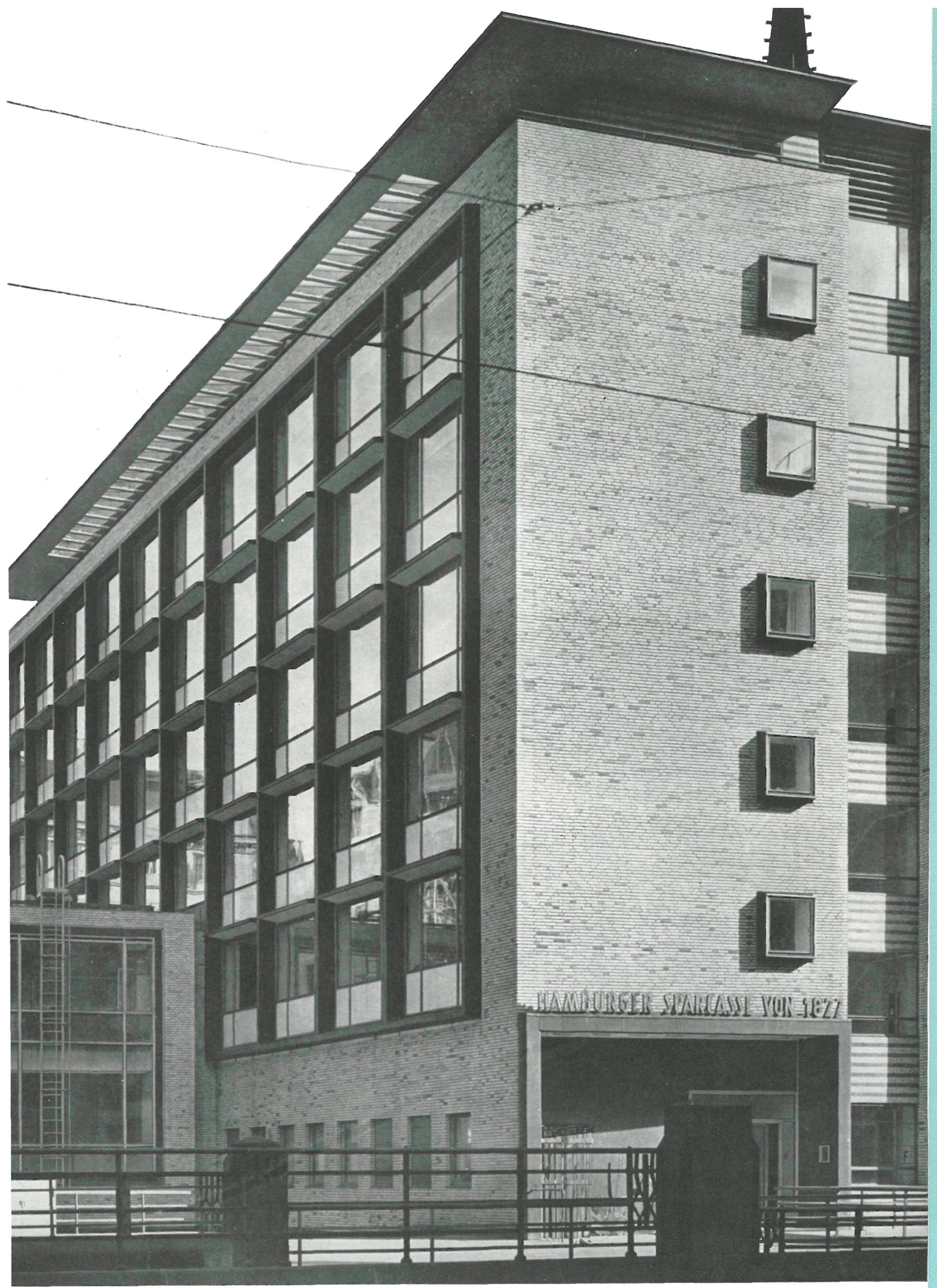

fachada

De esta especie de puente pende la estructura del corredor que circunda el gran hall, y éste, por consiguiente, está totalmente libre de apoyos. Para obtener una buena iluminación central, protegiendo, no obstante, la gran sala del calor y el sol, dentro se empotraron en el techo lucernarios en forma de casquetes semiesféricos de hormigón translúcido. Los pavés empleados son de cristal refringente isotérmico. El vestíbulo está, además, climatizado. Sus grandes muros, totalmente diáfanos, llevan cerramientos de carpintería metálica con doble luna. 
El edificio de oficinas es de siete plantas, y parte de su medianería posterior colindante con un viejo edificio. Las crujías de fachada quedan libres y se utilizaron para despachos. Las escaleras, vestíbulo, cajas de ascensores y otros locales secundarios se situaron en crujías interiores.

Merece especial mención la planta de sótano, en la cual se situó la caja fuerte de la Banca y a la que se llega a través de un sistema de rampas por las que circulan las vagonetas portadoras de sumas importantes de dinero y valores.

En un local de clasificación, las vagonetas pueden variar de dirección sobre una plataforma giratoria; este mecanismo hace que sea posible la descarga directa de todas ellas en la gran caja fuerte. El cierrê. de esta caja, de gran seguridad, es eléctrico.

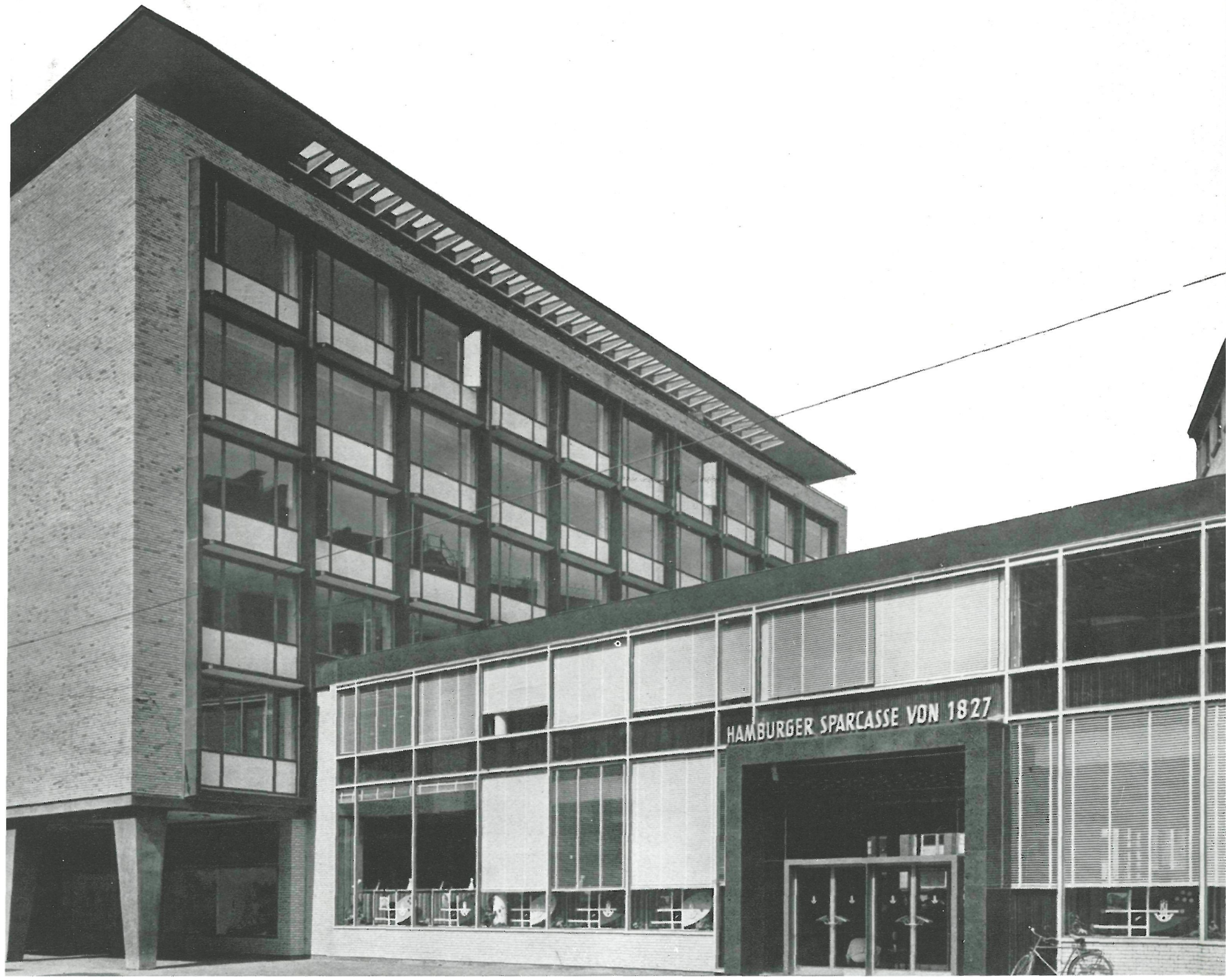




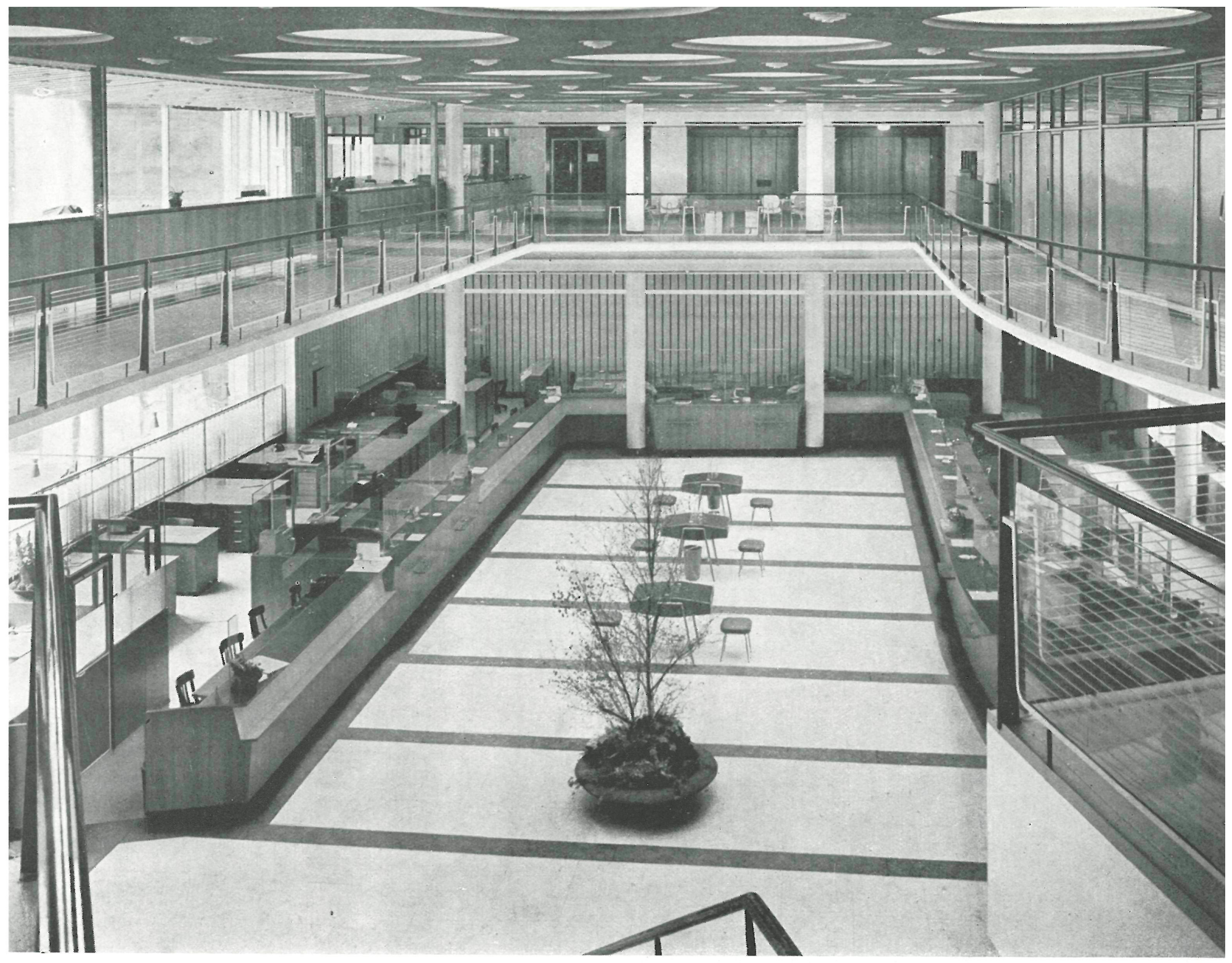

Interior del hall de operaciones.

Pórtico exterior.

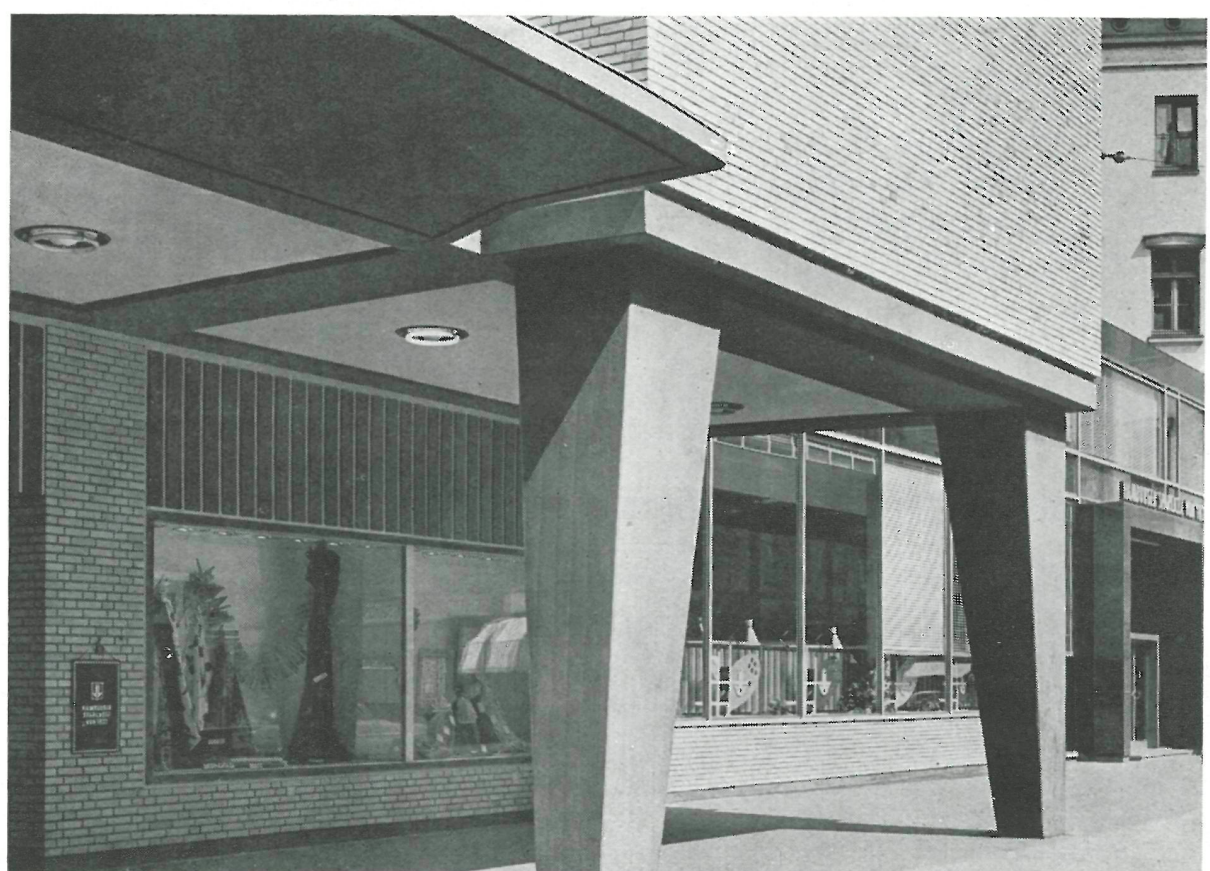




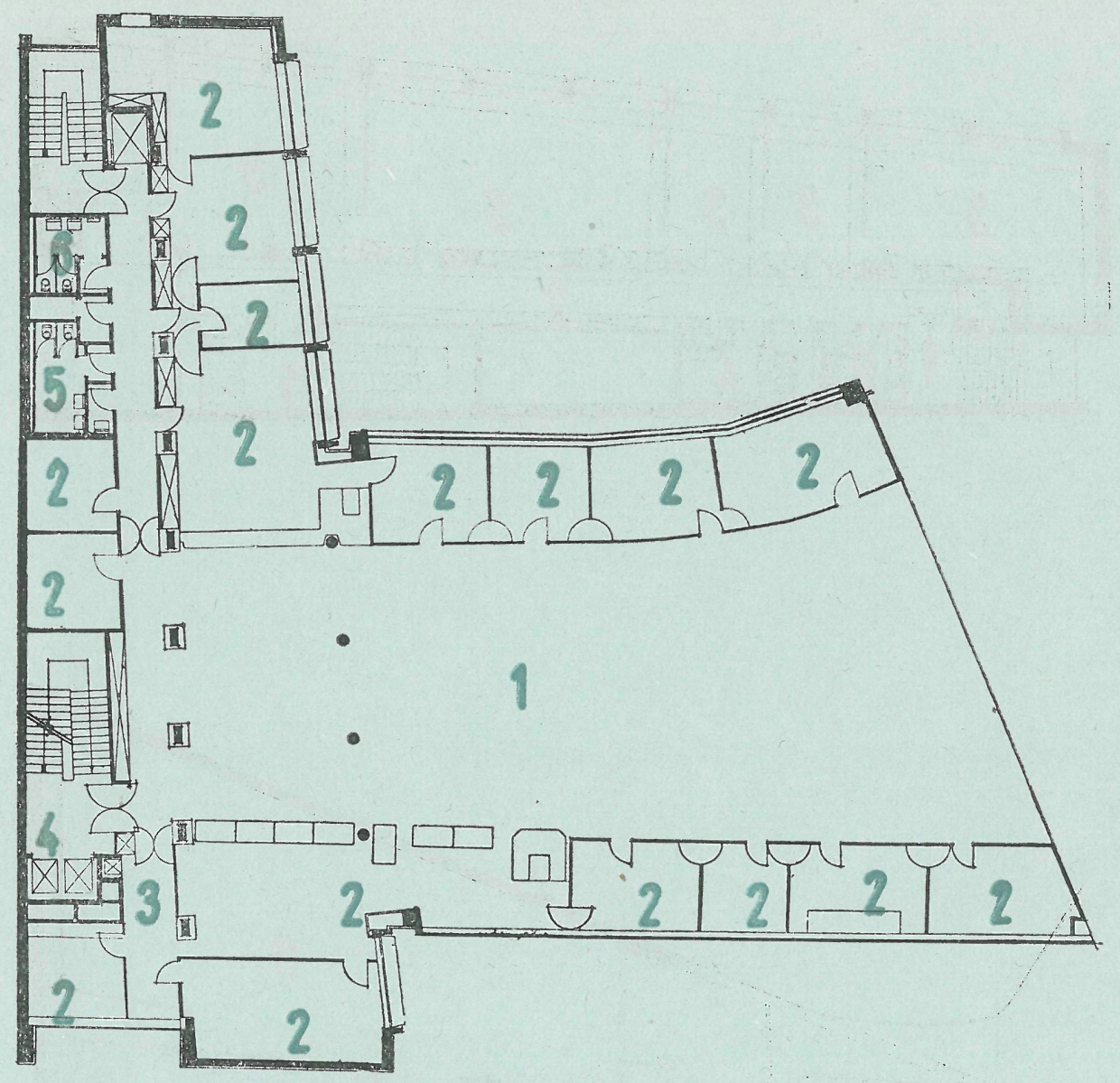

plantas

\section{principal}

1. Hueco del hall de operaciones.

2. Despachos y oficinas.

3. Intervención.

4. Montapapeles.

5. Vestíbulo de ascensor y escalera.

6. Aseo caballeros.

7. Aseo señoras.

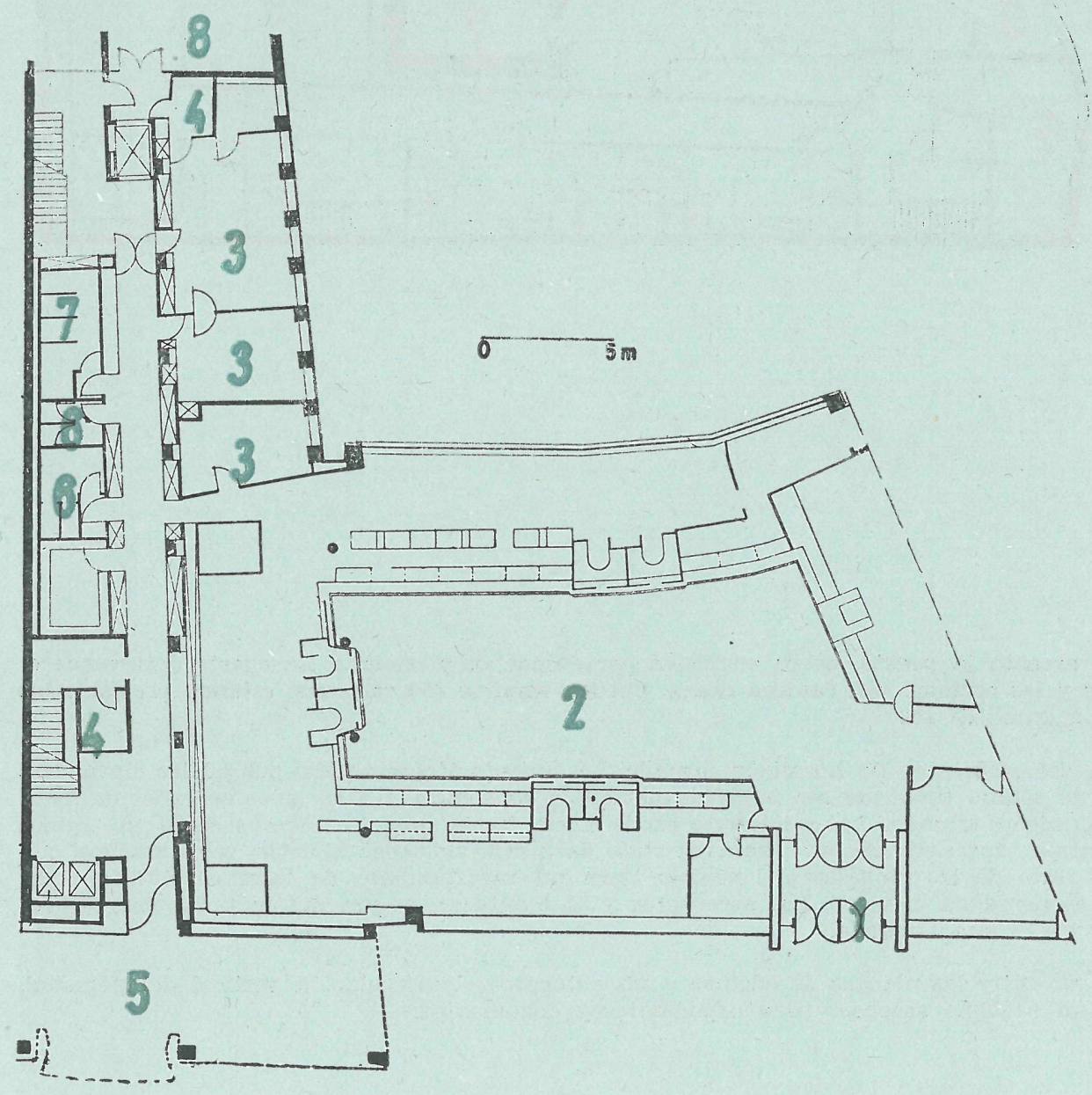

baja

1. Hall de operaciones.

2. Acceso principal.

3. Oficinas y despachos.

4. Portería.

5. Pórtico.

6. Aseo caballeros.

7. Aseo señoras. 


\section{plantas}

\section{de áticos}

1. Vestíbulo de escalera y ascensores.

2. Pasillo de distribución.

3. Despachos y oficinas.

4. Aseo caballeros.

5. Aseo señoras.

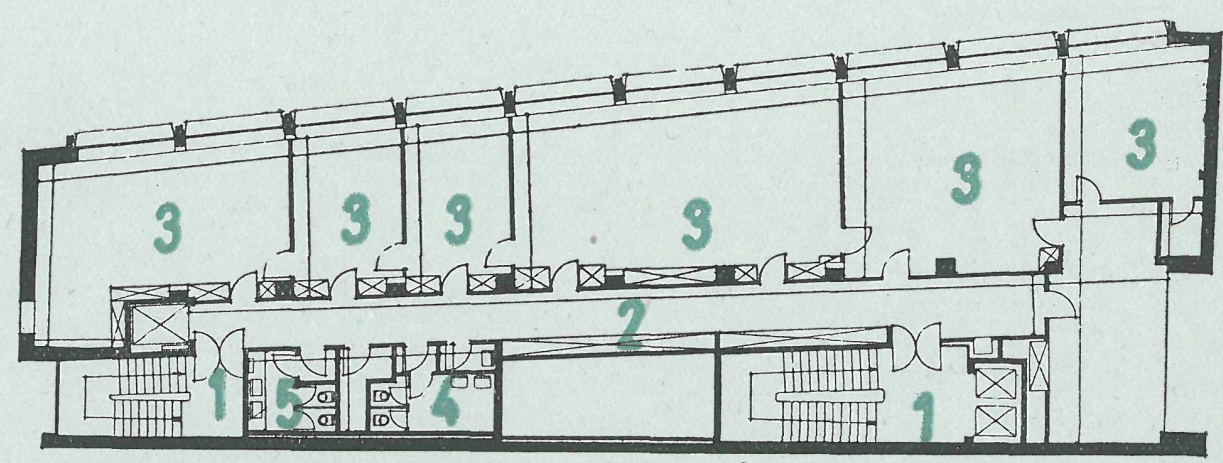

\section{de sótanos}

1. Duchas.

2. Aseos.

3. Refrigeración.

4. Taquillas.

5. Instalación de climatización.

6. Grupo electrógeno.

7. Caja fuerte.

8. Archivo general.

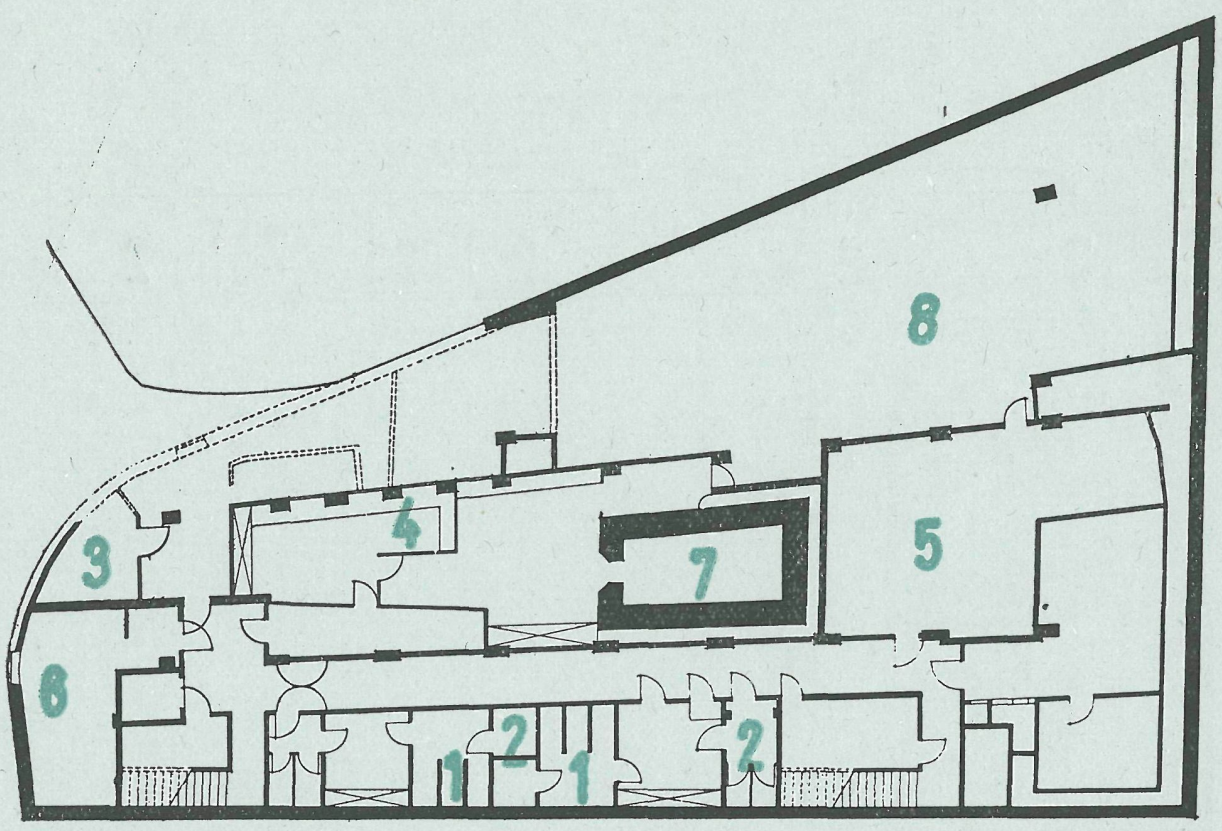

Todas las plantas, excepto la cuarta, están ocupadas por despachos y oficinas. La cuarta comprende el comedor de empleados y las cocinas, con cantina donde pueden servirse 450 raciones, estando previstas las instalaciones para un máximo de 850

Toda la estructura del edificio es de hormigón armado. La cimentación se realizó por pilotes clavados a martinete. La planta de sótano tuvo que ser impermeabilizada a conciencia. Los forjados nervados de todas las plantas son de hormigón armado. La carpintería es de acero inoxidable; los huecos están protegidos por pantallas de hormigón; sus antepechos se han revestido de piezas vidriadas blancas, y los machos, con pórfido negriverde. El resto de las fachadas del edificio lleva un revestimiento de ladrillos clínker amarillos. La calefacción es por agua caliente. Los ascensores y el montacargas son automáticos; este último puede elevar pesos de hasta una tonelada.

Para facilitar la labor entre las plantas de oficinas y no entorpecer la circulación vertical del personal, se le ha provisto de un pequeño ascensor para expedientes y documentos. 


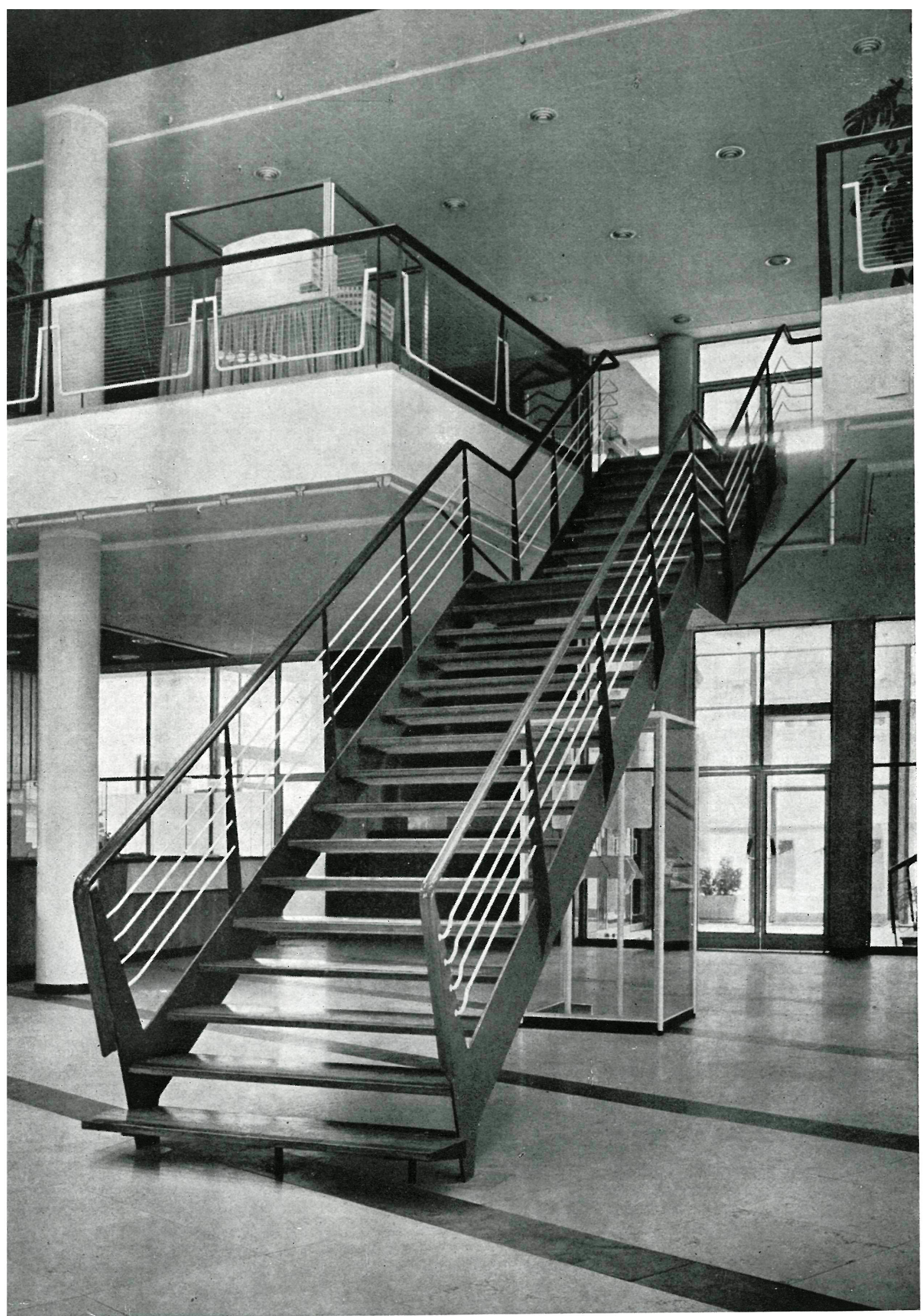

escalera 


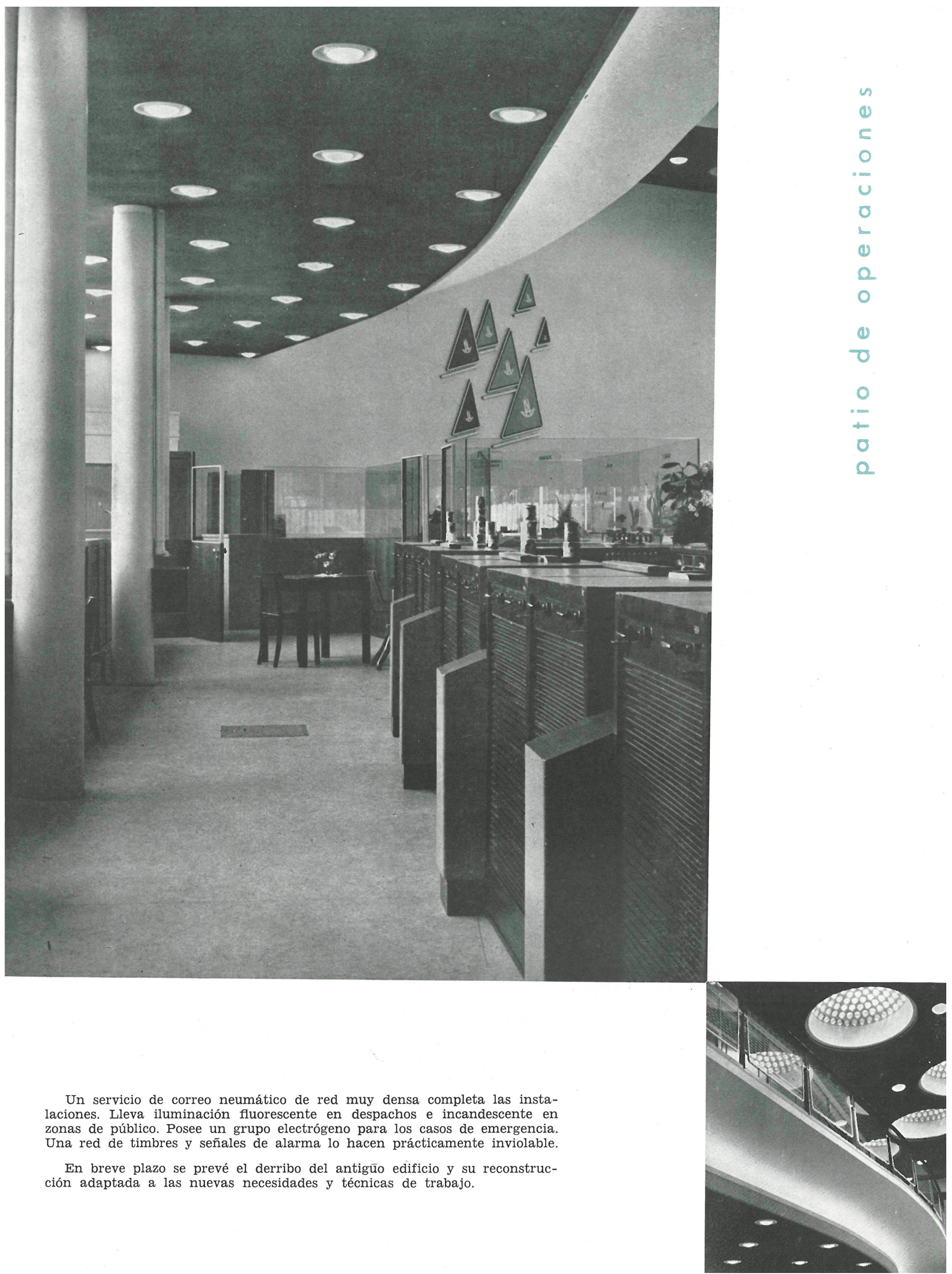




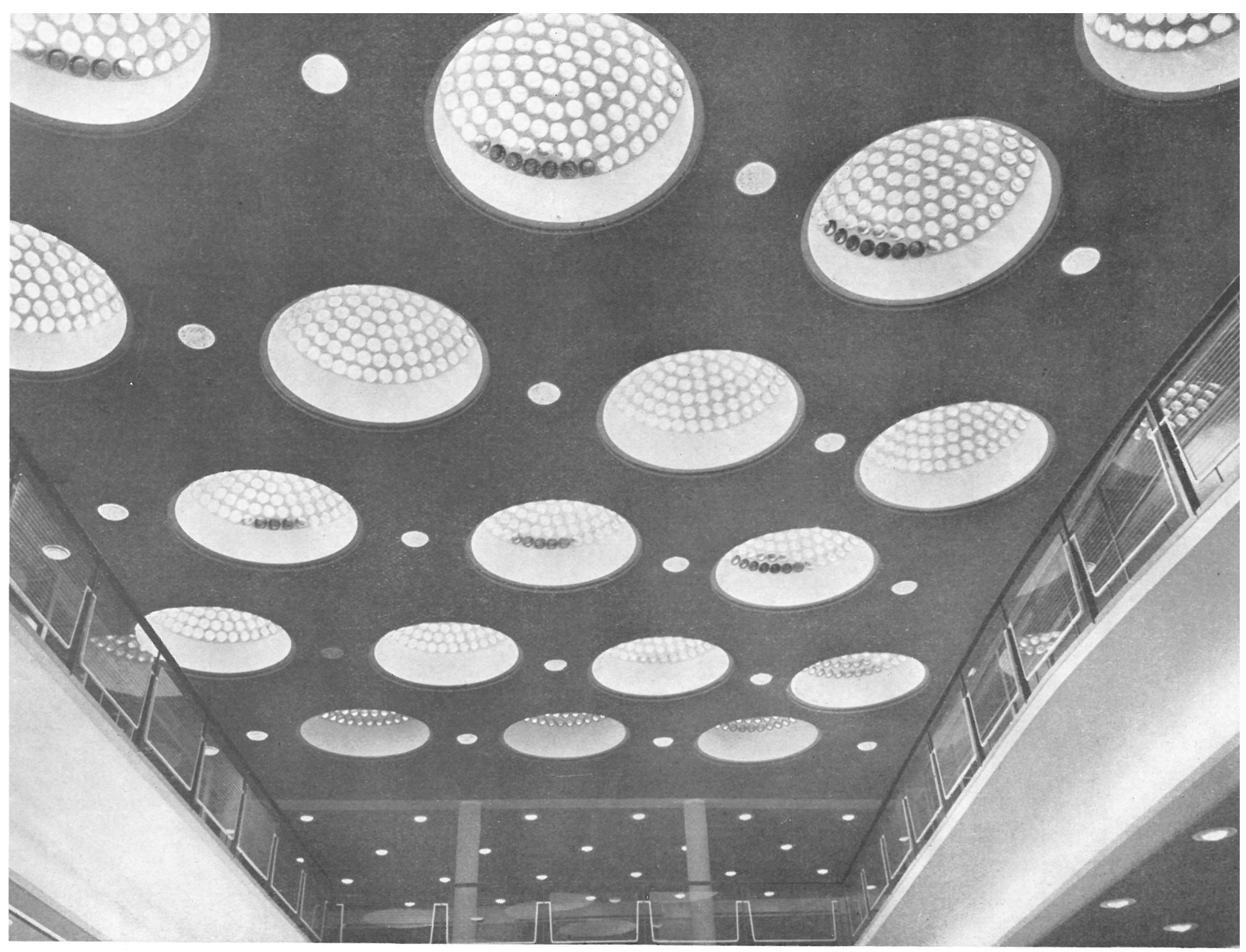

Fotos: E. SCHEEL, E. T OEgER y H. HEYER

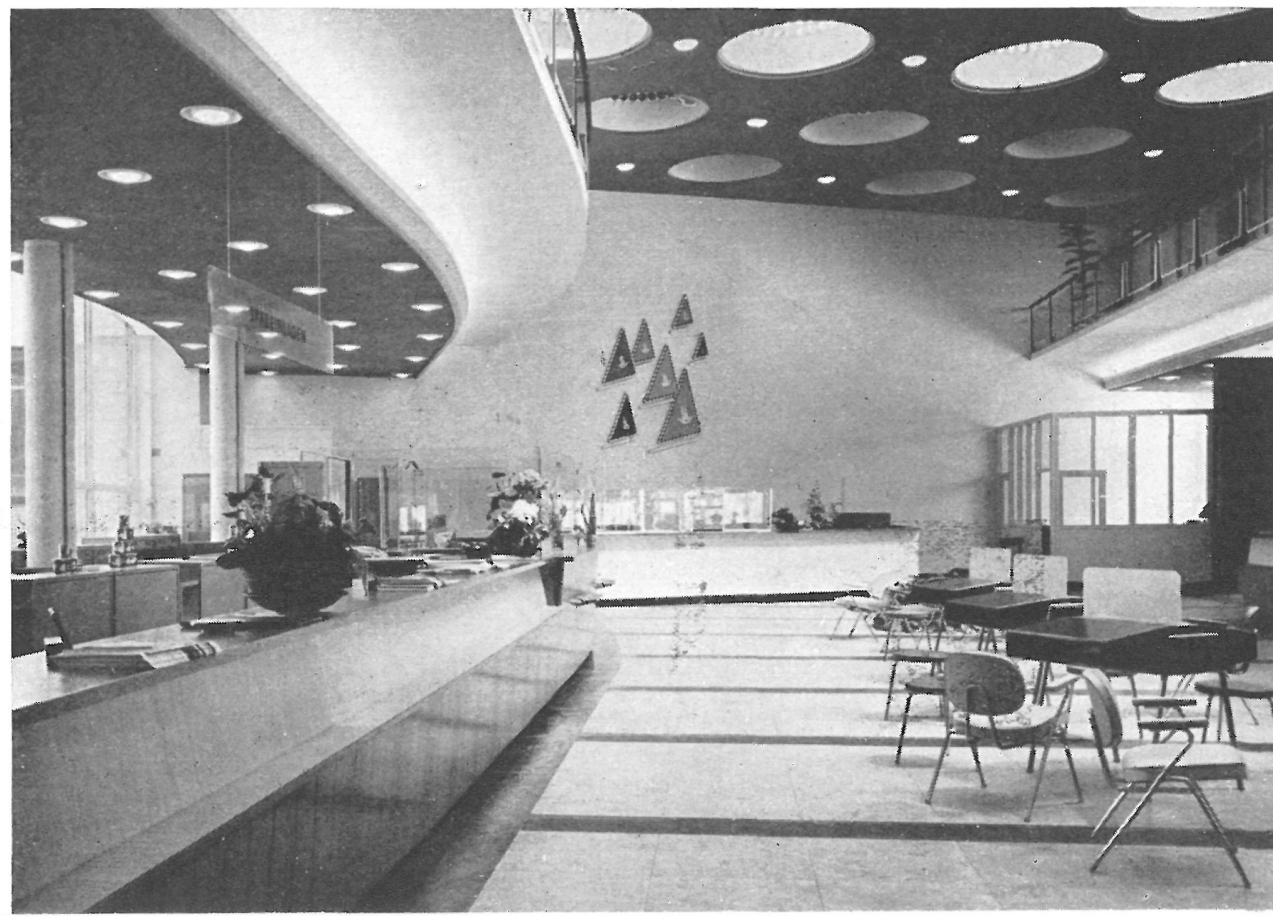

